\title{
ANALYZING THE INFLUENCING FACTORS OF SPORTS FATIGUE BASED ON ALGORITHM
}

\author{
ANÁLISE DOS FATORES QUE INFLUENCIAM A FADIGA ESPORTIVA BASEADA EM ALGORITIMKI \\ LA TECNOLOGÍA DE RETROALIMENTACIÓN BIOLÓGICA BASADA EN ALGORITMOS
}

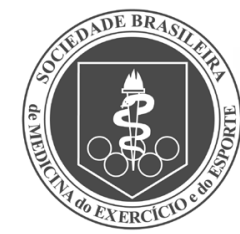

Original Article

ARTIGO ORIGINAL

Artículo Original

\section{Cheng Wang' (iD \\ (Physical Education Professional) \\ 1. Northwestern Polytechnical University, Xi'an, China.}

\section{Correspondence:}

Cheng Wang

Northwestern Polytechnical

University, Xi'an, China.

wangchenghn@yeah.net

\begin{abstract}
Objective: This paper discusses the monitoring method of exercise fatigue and analyzes the influencing factors of exercise fatigue. Methods: Based on the feature extraction method of the fatigue image signal, a series of changes caused by exercise fatigue are analyzed by the biofeedback technique. SVM algorithm and neural network model are used to identify the fatigue state of motion. Characteristics of electroencephalogram (EEG) and electromyography (EMG) during fatigue. Results: When sports fatigue occurred, the composite index of bio-feedback technology shows a decrease in HRV index and increases in HRV time-domain indicators, frequency-domain indicators, and SAa values. Conclusions: It has a high degree of systematization. The proposed method is non-invasive and has practical application value. Level of evidence II; Therapeutic studies - investigation of treatment results.
\end{abstract}

Keywords: Electroencephalography; Electromyography; Muscle fatigue.

\section{RESUMO}

Objetivo: este artigo discute o método de monitoramento da fadiga do exercício e analisa os fatores que influenciam a fadiga do exercício. Métodos: Com base no método de extração de características do sinal da imagem da fadiga, uma série de alterações causadas pela fadiga do exercício são analisadas pela técnica de biofeedback. O algoritmo SVM e o modelo de rede neural são usados para identificar o estado de fadiga do movimento. Características do eletroencefalograma (EEG) e eletromiografia (EMG) durante a fadiga. Resultados: Quando a fadiga esportiva ocorreu, o índice composto da tecnologia de bio-feedback mostra uma diminuição no índice de VFC e aumentos nos indicadores de VFC no domínio do tempo, indicadores no domínio da frequência e valores SAa. Conclusões: Possui alto grau de sistematização. O método proposto é não invasivo e tem valor de aplicação prática. Nível de evidência Il; Estudos terapêuticos- investigação dos resultados do tratamento.

Descritores: Eletroencefalografia; Eletromiografia; Fadiga muscular.

\section{RESUMEN}

Objetivo: Este artículo analiza el método de seguimiento de la fatiga por ejercicio y analiza los factores que influyen en la fatiga por ejercicio. Métodos: Basado en el método de extracción de características de la señal de la imagen de fatiga, se analizan una serie de cambios causados por la fatiga del ejercicio mediante la técnica de biorretroalimentación. El algoritmo SVM y el modelo de red neuronal se utilizan para identificar el estado de movimiento de fatiga. Características del electroencefalograma (EEG) y electromiografía (EMG) durante la fatiga. Resultados: cuando se produjo la fatiga deportiva, el índice compuesto de la tecnología de bio-retroalimentación muestra una disminución en el índice de HRV y aumentos en los indicadores de dominio de tiempo de HRV, indicadores de dominio de frecuencia y valores de SAa. Conclusiones: Tiene un alto grado de sistematización. El método propuesto no es invasivo y tiene un valor de aplicación práctica. Nivel de evidencia Il; Estudios terapéuticos-investigación de los resultados del tratamiento.

Descriptores: Electroencefalografía; Electromiografía; Fatiga muscular.

\section{INTRODUCTION}

The basic signs of exercise fatigue are the decline in muscle exercise ability, which is a physiological phenomenon caused by intramuscular contraction, or the maximum output power caused by motion. ${ }^{1}$ At present, research on physical fatigue diagnosis methods has always been a hot topic of scholars in the field of exercise. ${ }^{2}$ During exercise, the fatigue level of the human body will gradually deepen. At the same time, mycardium and oxygen signal signals will change. By studying the changes of these biological signals during exercise, the biological indicators associated with sports fatigue are extracted, and the monitoring of human sports fatigue is achieved. ${ }^{3-5}$

This study focuses on biofeedback techniques based on feature images to understand the application of this technique in 
non-intrusive monitoring of fatigue time and corresponding exercise intensity. ${ }^{6}$ In addition, it confirms its reliability and comprehensiveness.

\section{METHODS}

\section{Construction of experimental model}

This study randomly selected 14 college student athletes from grade 2018, who were divided into the men's group and the women's group, with 7 athletes in each group. The general materials about the age, height, weight and years of exercise of all the included athletes are shown in Table 1. Before the experiment officially started, it must be guaranteed that all the research objects had no insomnia, heavy drinking, heavy training, or competition within 48 hours. After general medical examinations, it was determined that the athletes had no clinical medical conditions or sports system damages that were not suitable for high-intensity exercise. After being familiar with the experimental procedure and clarifying the research risks, all subjects voluntarily signed informed consent forms.

The exercise was started at a speed of $2.7 \mathrm{~km} / \mathrm{h}$ and a maximum slope of $10 \%$. Then, it was increased by one level every 3 minutes. The entire exercise plan had 7 levels and the final speed would reach $9.6 \mathrm{~km} / \mathrm{h}$, and the final slope would reach 22\%. Table 2 shows the details of the Bruce scheme at each level. During the experiment, the occurrence of sports fatigue could be determined once the athletes could not continue to maintain the exercise intensity, and their reaction time, the rating of perceived exertion (RPE), and the instant maximum heart rate reached the fatigue value. The German h/p/ cosmos pulsar 4.0 sports treadmill was used to control the exercise intensity. The Austrian SCHUHFRTED biological feedback instrument

Table 1. General materials of the research objects.

\begin{tabular}{c|c|c}
\hline Category & Male & Female \\
\hline Age & $19.98 \pm 0.78$ & $19.75 \pm 0.66$ \\
\hline Height $(\mathrm{m})$ & $1.73 \pm 0.06$ & $1.61 \pm 0.05$ \\
\hline Weight $(\mathrm{kg})$ & $65.33 \pm 5.82$ & $54.08 \pm 5.03$ \\
\hline Exercise years & $3.76 \pm 1.27$ & $3.69 \pm 1.36$ \\
\hline
\end{tabular}

Table 2. Factors influencing the classic Bruce scheme of running platform.

\begin{tabular}{c|c|c}
\hline Level & Speed $(\mathbf{k m} / \mathbf{h})$ & Slope (\%) \\
\hline 1 & 2.7 & $10 \%$ \\
\hline 2 & 4.0 & $12 \%$ \\
\hline 3 & 5.4 & $14 \%$ \\
\hline 4 & 6.7 & $15 \%$ \\
\hline 5 & 8.0 & $18 \%$ \\
\hline 6 & 8.8 & $20 \%$ \\
\hline 7 & 9.6 & $22 \%$ \\
\hline
\end{tabular}

was used to collect body surface electrical signal data. The Finland SUUNTO remote heart rate telemetry team system was used to collect instant maximum heart rate.

\section{Bioelectric signal acquisition technology}

Bioelectric signal is a very weak $\mathrm{uV} \sim \mathrm{mV}$ level signal, which is extremely susceptible to external interference and interference between signals. Therefore, in the process of bioelectric signal acquisition, it is necessary to suppress the noise interference while multi-level amplification of the signal. ${ }^{7}$

The amplitude of the ECG signal directly collected from the human body surface is very weak, which is about $1 \mathrm{mV}$. The frequency range is mainly distributed between $0.1 \sim 100 \mathrm{~Hz}$. The structure of the ECG signal acquisition system designed in this study is shown in Figure 1. This design can effectively suppress noise interference and perform two-stage amplification of the ECG signal.

The main module of the EMG signal acquisition system includes signal acquisition and processing, analog-to-digital conversion, and data transmission. ${ }^{8}$ The specific system structure is shown in Figure 2.

\section{Feature extraction and evaluation algorithm for sports fa- tigue image signals}

In this study, the features of the ECG and EMG signals were extracted from time and frequency domains, respectively. In addition, the tendency of different characteristic indicators of two signals in different fatigue states in the human body is analyzed. The ECG signal is extracted for an indicator such as a heart rate and an HRV, while the EMG signal is used in an indicator such as a root average value (RMS) and an integrated electric tap (IEMG). ECG signal extraction mainly includes extracting the ratio of high frequency power (HF), low frequency power (LF), low frequency power and high frequency power (LF / HF), and other indicators. The EMG signal mainly extracts average power frequency (MPF), median (MF), and other indicators.

In this study, the Support Vector Machine (SVM) algorithm and neural network model were selected to distinguish between motion fatigue. During the classification process, the point away from the super plane is safe, and the idea of SVM is focused on near the super plane, that is, the distance between the closest to the super plane and the super plane, the target can be expressed as:

$$
\begin{array}{ll}
\max _{w, b} & \gamma \\
\text { s.t. } & \gamma_{i}\left(\frac{w}{\|w\|} \llbracket x_{i}+\frac{b}{\|w\|}\right) \geq \gamma, \quad i=1,2, \ldots, N
\end{array}
$$

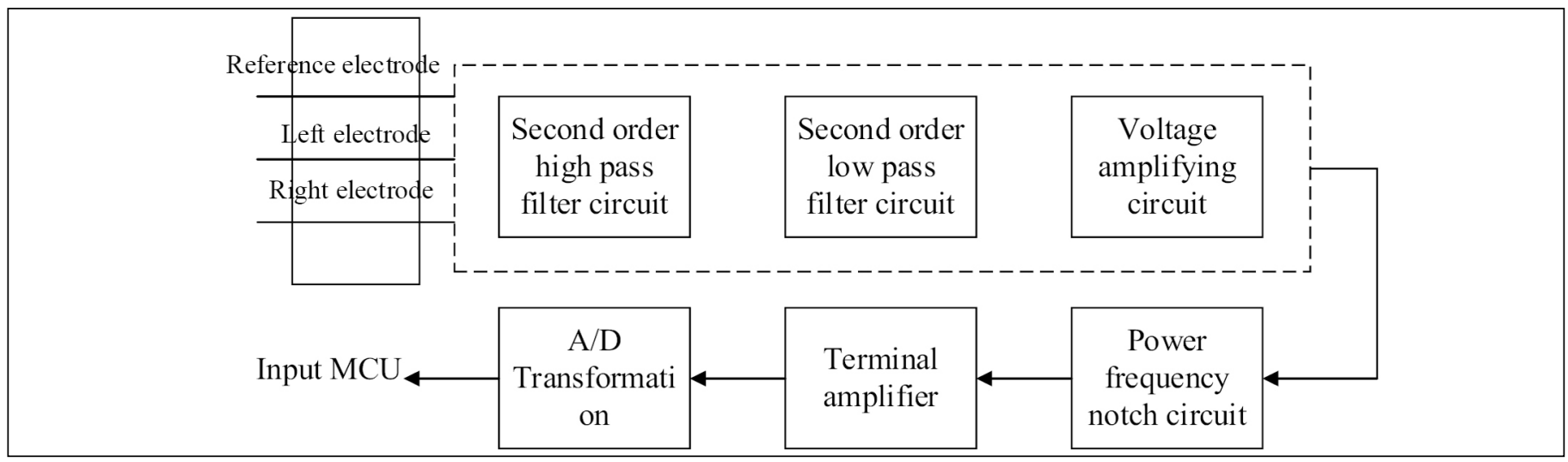

Figure 1. The structure of ECG signal acquisition system. 


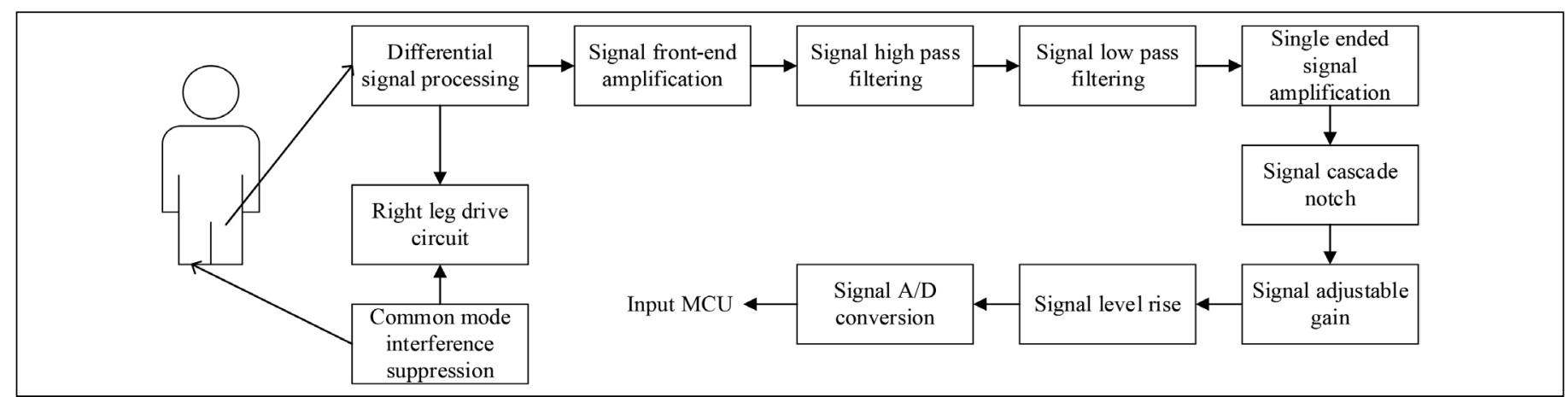

Figure 2. Structure of the EMG signal acquisition system.

$\gamma$ is the geometric interval from the point closest to the hyperplane to the hyperplane. Substituting the geometric interval with a function interval, the equation can be expressed as:

\begin{tabular}{|l}
$\max _{w, b} \frac{\hat{\gamma}}{\|w\|}$ \\
s.t. $\quad \gamma_{i}\left(w \square x_{i}+b\right)-1 \geq 0, \quad i=1,2, \ldots, N$ \\
\hline
\end{tabular}

According to the convex optimization theory, the constraint problem can be solved into an unconstrained problem with the help of Lagrange function. The optimization function can be expressed as:

$$
L(w, b, \alpha)=\frac{1}{2}\|w\|^{2}-\sum_{i=1}^{N} \alpha_{i} \gamma_{i}\left(w \llbracket x_{i}+b\right)+\sum_{i=1}^{N} \alpha_{i}
$$

$\alpha_{i} \geq 0 \quad i=1,2, \ldots, N$

Where: $\alpha_{i}$ is the Lagrange multiplier. According to the duality of Lagrange, the original problem can be transformed into a dual problem (As long as the dual problem exists, the optimal solution of the dual problem is the optimal solution of the original problem. Generally, the dual problems are easier to be solved than the original problems), i.e., the minimax problem:

$$
\max _{\alpha} \min _{w, b} L(w, b, \alpha)
$$

First, the minimum and derivative problem of $w$ and $b$ are solved. Then, the value of $w$ and $b$ can be obtained:

$$
w=\sum_{i=1}^{N} \alpha_{i} \gamma_{i} x_{i}
$$

$$
\sum_{i=1}^{N} \alpha_{i} \gamma_{i}=0
$$

Therefore, if the value of $\alpha$ is obtained, the values of $w$ and $b$ will also be obtained. The parameters $w$ and $b$ are only related to the satisfied samples of $\gamma_{i}\left(w+x_{i}+b\right)-1=0$. These sample points are the points closest to the maximum interval hyperplane, which are called support vectors. Therefore, the support vector can often perform well in the classification of small sample sets.
The SVM algorithm is robust, relatively simple, and suitable for solving small sample binary classification problems. The long-term and short-term memory network (LSTM) model is suitable for information modeling of ordered features, which can perform effective feature extraction, classification, recognition, and prediction on input data.

\section{Experimental Process}

The participant first performed a full squat exercise, whose EMG and ECG signals of the lower limb-related muscles under different exercise intensities were obtained by the surface bioelectric sensor. The signals were converted into a digital signal by a bioelectric signal acquisition system and transmitted to a host computer. The Borg subjective fatigue consciousness scale was used to obtain subjective information on sports fatigue, i.e., the RPE value was used as a classification index for different sports fatigue states.

The sports fatigue experiment designed in this study was the lower limb aerobic exercise experiment, which mainly involved the lower limb muscle groups. The thigh muscle group plays the most important role in the actuation of the knee joint. For the convenience of detection, a muscle with a broad thigh muscle surface and a direct relationship with knee flexion and extension was selected as the detection site. Three thigh muscles related to squat exercise were selected for experimental analysis. (Figure 3)

During the exercise, the ECG electrodes were placed on the chest in close contact with the skin. LA and RA were the left and right input electrodes, respectively, and $R L$ was the reference electrode.

\section{Image processing and data statistics methods}

In this study, the SPSS 21.0 statistical software was used for data and image processing. The count data were expressed as (mean \pm standard deviation). The collected data were analyzed by independent sample $T$ test and One-way ANOVA. The difference was statistically significant at $P<0.05$.
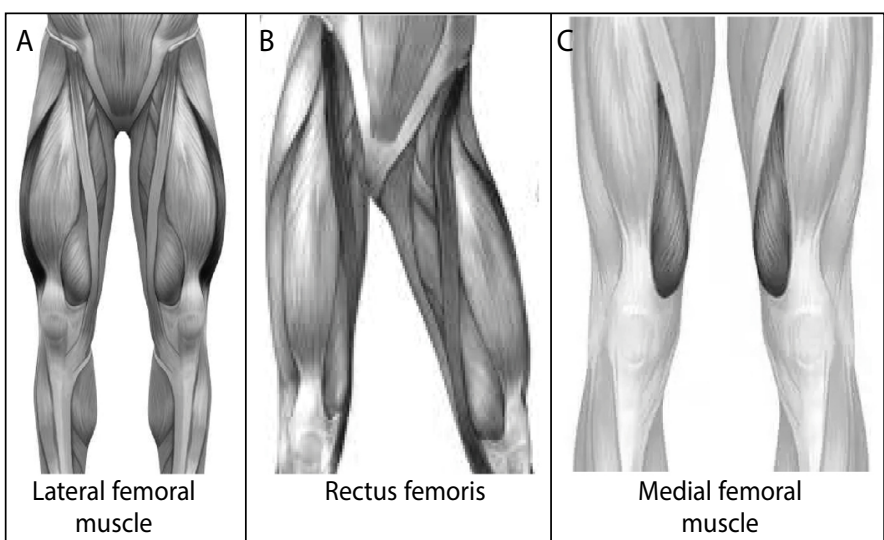

Figure 3. Thigh muscle distribution. 


\section{RESULTS}

\section{Characteristic changes in HRV index value of sports fatigue bio-feedback technology}

Table 3 compares the results of HRV bio-feedbackindicators in the men's and women's groups under quiet, fatigued, and recovered conditions. It can be seen that the HRV index of the two groups decreased significantly in fatigued condition, which was significantly different from that at rest, with statistical significance $(P<0.05)$. HRV time-domain indicators SDNN, RMSSD, PNN50, and frequency-domain indicators $L F, H F, L F / H F$, and SAa all increased, but the differences between the two groups were not significant. This shows that when sports fatigue occurs, the HRV index of the two groups decreases significantly. At this time, HRV time-domain and frequency-domain indicators and sinus arrhythmia increase.

\section{Characteristic changes in SEMG index of sports fatigue bio- -feedback technology}

Table 4 compares the results of the sEMG bio-feedback indicators of the men's and women's groups under quiet, fatigued, and recovered conditions. As shown in the table, under the fatigued state, when the values of IEMG1 and RMS1 of the men's group did not increase significantly, and MPF1 and MF1 decreased significantly, the values of IEMG2 and RMS2 increased significantly $(P<0.05)$, and the values of MPF 2 and

Table 3. Comparison of HRV indicators between two groups of athletes in different states.

\begin{tabular}{|c|c|c|c|}
\hline State & Waveform category & Men's group & Women's group \\
\hline \multirow{8}{*}{ Quiet } & HRV & $6.50 \pm 1.06$ & $6.20 \pm 1.09$ \\
\hline & SDNN (ms) & $169.33 \pm 35.59$ & $166.69 \pm 53.15$ \\
\hline & SDSD (ms) & $99.10 \pm 50.47$ & $110.88 \pm 82.39$ \\
\hline & $\mathrm{SAa}(\mathrm{ms})$ & $82.19 \pm 33.78$ & $97.03 \pm 53.18$ \\
\hline & PNN50 (\%) & $43.38 \pm 8.96$ & $45.60 \pm 7.79$ \\
\hline & LF (ms2) & $536.48 \pm 210.76$ & $620.08 \pm 256.78$ \\
\hline & $\mathrm{HF}$ (ms2) & $520.39 \pm 318.54$ & $634.79 \pm 518.94$ \\
\hline & $\mathrm{LF} / \mathrm{HF}$ & $1.34 \pm 1.04$ & $1.66 \pm 1.17$ \\
\hline \multirow{8}{*}{ Fatigue } & HRV & $4.53 \pm 1.28$ & $4.06 \pm 1.10$ \\
\hline & SDNN (ms) & $188.65 \pm 62.20$ & $178.55 \pm 63.32$ \\
\hline & SDSD (ms) & $139.67 \pm 73.45$ & $128.03 \pm 81.19$ \\
\hline & $\mathrm{SAa}(\mathrm{ms})$ & $110.35 \pm 52.06$ & $100.98 \pm 52.45$ \\
\hline & PNN50 (\%) & $47.37 \pm 12.67$ & $45.78 \pm 15.56$ \\
\hline & LF (ms2) & $765.38 \pm 347.38$ & $620.98 \pm 180.03$ \\
\hline & $\mathrm{HF}(\mathrm{ms} 2)$ & $904.47 \pm 545.67$ & $773.39 \pm 538.19$ \\
\hline & $\mathrm{LF} / \mathrm{HF}$ & $1.41 \pm 1.09$ & $1.65 \pm 1.46$ \\
\hline \multirow{8}{*}{ Recovery } & HRV & $7.01 \pm 2.80$ & $6.07 \pm 2.11$ \\
\hline & SDNN (ms) & $211.29 \pm 67.38$ & $192.35 \pm 59.46$ \\
\hline & SDSD (ms) & $150.35 \pm 72.31$ & $133.45 \pm 81.79$ \\
\hline & $\mathrm{SAa}(\mathrm{ms})$ & $133.64 \pm 51.78$ & $115.78 \pm 54.39$ \\
\hline & PNN50 (\%) & $56.89 \pm 9.08$ & $51.48 \pm 7.94$ \\
\hline & $\mathrm{LF}(\mathrm{ms} 2)$ & $834.57 \pm 300.04$ & $747.18 \pm 287.32$ \\
\hline & $\mathrm{HF}$ (ms2) & $929.78 \pm 508.33$ & $855.39 \pm 645.37$ \\
\hline & $\mathrm{LF} / \mathrm{HF}$ & $1.44 \pm 1.17$ & $1.67 \pm 1.38$ \\
\hline
\end{tabular}

Table 4. Comparison of sEMG indicators between two groups of athletes in different. States.

\begin{tabular}{|c|c|c|c|}
\hline State & Waveform category & Men's group & Women's group \\
\hline \multirow{8}{*}{ Quiet } & IEMG1 & $0.75 \pm 0.58$ & $0.66 \pm 0.71$ \\
\hline & RMS1 & $1.19 \pm 1.13$ & $1.03 \pm 0.88$ \\
\hline & MPF1 & $91.98 \pm 21.32$ & $106.58 \pm 10.63$ \\
\hline & MF1 & $52.34 \pm 7.28$ & $53.28 \pm 5.05$ \\
\hline & IEMG2 & $0.84 \pm 0.42$ & $0.7 \pm 0.69$ \\
\hline & RMS2 & $1.39 \pm 0.55$ & $1.09 \pm 0.85$ \\
\hline & MPF2 & $91.77 \pm 16.35$ & $96.34 \pm 13.00$ \\
\hline & MF2 & $48.22 \pm 4.78$ & $52.25 \pm 8.34$ \\
\hline \multirow{8}{*}{ Fatigue } & IEMGI & $2.11 \pm 1.78$ & $2.06 \pm 1.70$ \\
\hline & RMS1 & $2.89 \pm 1.99$ & $2.73 \pm 1.85$ \\
\hline & MPF1 & $76.39 \pm 8.20$ & $73.19 \pm 10.78$ \\
\hline & MF1 & $43.70 \pm 8.31$ & $44.94 \pm 5.06$ \\
\hline & IEMG2 & $3.11 \pm 2.48$ & $2.07 \pm 0.81$ \\
\hline & RMS2 & $3.89 \pm 2.79$ & $2.66 \pm 0.93$ \\
\hline & MPF2 & $79.03 \pm 8.35$ & $77.19 \pm 8.08$ \\
\hline & MF2 & $43.90 \pm 11.01$ & $45.50 \pm 7.75$ \\
\hline \multirow{8}{*}{ Recovery } & IEMG1 & $1.65 \pm 1.06$ & $1.29 \pm 0.77$ \\
\hline & RMS1 & $2.33 \pm 1.47$ & $2.05 \pm 1.18$ \\
\hline & MPF1 & $100.90 \pm 10.02$ & $97.98 \pm 9.02$ \\
\hline & MF1 & $51.13 \pm 8.35$ & $50.04 \pm 6.83$ \\
\hline & IEMG2 & $2.01 \pm 1.19$ & $1.44 \pm 0.52$ \\
\hline & RMS2 & $2.82 \pm 1.44$ & $2.12 \pm 0.68$ \\
\hline & MPF2 & $92.35 \pm 13.69$ & $96.03 \pm 10.88$ \\
\hline & MF2 & $54.27 \pm 5.98$ & $45.98 \pm 7.56$ \\
\hline
\end{tabular}

MF2 decreased. In the fatigued state, when the IEMG1 and RMS1 of the women's group increased significantly, MPF1 decreased significantly, and MF1 decreased, the values of IEMG2 and RMS2 increased significantly $(P<0.05)$. Also, the values of MPF2 and MF2 decreased, and the decrease of MPF2 was more significant $(P<0.05)$.

\section{DISCUSSION}

This study mainly explores the method based on signal feature extraction of fatigue images, and analyzes a series of changes caused by motor fatigue by using biological feedback technology. This study includes experimental modeling and empirical studies of bio feedback techniques for exercise fatigue by 14 college student athletes. It is shown that the composite index of the bio feedback technique shows that the HRV index decreases and the SAA value increases when motion fatigue occurs.

\section{CONCLUSION}

Biofeedback technology based on image signal feature extraction has strong scientific and time benefit in monitoring exercise fatigue. Moreover, it has a high degree of systematization. The method is non-invasive and has practical application value.

The author declare no potential conflict of interest related to this article

AUTHORS' CONTRIBUTIONS: Cheng Wang discusses the monitoring method of exercise fatigue and analyzes the influencing factors of exercise fatigue, analyzed a series of changes caused by exercise fatigue based on the method of feature extraction of fatigue image signal.

\section{REFERENCES}

1. O'Reilly MA, Slevin P, Ward T, Caulfield B. A Wearable Sensor-Based Exercise Biofeedback System: Mixed Methods Evaluation of Formulift. JMIR Mhealth Uhealth. 2018;6(1):e33.

2. Nazali MN, Ling LP. Autotuned electrical muscle stimulator with electromyogram biofeedback. ELEKTRIKA-Journal of Electrical Engineering. 2017;16(2);34-8.

3. Barandas M, Gamboa H, Fonseca JM. A real time biofeedback system using visual user interface for physical rehabilitation. Procedia Manufacturing. 2015;3:823-8.

4. Correia FD, Nogueira A, Magalhães I, Guimarães J, Moreira M, Barradas I, et al. Home-based rehabilitation with a novel digital biofeedback system versus conventional in-person rehabilitation after total knee replacement: A feasibility study. Scientific Reports. 2018;8(1):11299.
5. Al-Mulla MR. Wearable devices for improved health care systems based on biomedical technology Journal of Biomedical Systems \& Emerging Technologies. 2016;3(1):

6. Park S, Hetzler T, Hammons D, Ward G. Effects of biofeedback postural training on pre-existing low back pain in static-posture workers. J Back Musculoskelet Rehabil. 2018;31(5):849-857.

7. Antunes A, Carnide F, Matias R. Real-time kinematic biofeedback improves scapulothoracic control and performance during scapular-focused exercises: A single-blind randomized controlled laboratory study. Hum Mov Sci. 2016;48:44-53.

8. Mackay AM, Buckingham R, Schwartz RS, Hodgkinson S, Beran RG, Cordato DJ. The Effect of Biofeedback as a Psychological Intervention in Multiple Sclerosis: A Randomized Controlled Study. Int J MS Care. 2015;17(3):101-8. 